УДК 159.9

DOI: $10.17223 / 17267080 / 66 / 2$

\title{
О.Н. Попова
}

Городской иентр психолого-педагогической поддержки молодежи «Родник» (Новосибирск, Россия)

\section{Проблема сбалансированности временной перспективы личности}

\begin{abstract}
Представлены результаты исследований проблемы временной перспективы личности в аспекте изучения мотивачионных установок. Предложено описание качественных характеристик временной перспективы личности относительно насыщенности мотивационными объектами отдельных темпоральных зон. Рассмотрены различные варианты сбалансированности временной перспективы и их взаимозависимость с активностью личности. Уточнена постановка проблемы сбалансированности временной перспективы.

Ключевые слова: временная перспектива; мотивационные объекты; темпоральные зоны; сбалансированность временной перспективы; направленность мотивачионных объектов; протяженность временной перспективы.
\end{abstract}

В последнее десятилетие в зарубежных и отечественных научных работах отмечается рост внимания к феномену психологического времени и временной перспективы как характеристике личности [1. С. 54]. В современной науке проблема временной перспективы рассматривается в широком диапазоне подходов, в том числе исследуются:

- аффективные аспекты временной перспективы, связанные с эмоциональным отношением к событиям прошлого и настоящего (Ф. Зимбардо, Дж. Бойд, М.Р. Хачатурова, А.К. Болотова и др);

- особенности восприятия субъективного времени жизни и его организации (К.А. Абульханова-Славская, Т.Н. Березина, Л.П. Караваева, А.Н. Афанасьева и др.);

- перспективы будущего как мотивационной установки, влияющей на достижение цели (Ж. Нюттен, В. Ленс, Т. Гисме, З. Залески);

- структура межсобытийных связей (Е.И. Головаха и А.А. Кроник);

- переживание экзистенциальных смыслов существования во всей протяженности времени между прошлым и будущим (О.В. Лукьянов) и др.

Большинство исследований временной перспективы в отечественных научных работах направлены на изучение взаимосвязи эмоционального восприятия прошлого, настоящего и будущего с личностными и субъективными характеристиками, в то же время в значительно меньшей степени представлены исследования временной перспективы как мотивационной установки [2-6]. До настоящего времени сбалансированность (гармоничность) временной перспективы рассматривалась с позиции эмоционального отношения к временным периодам жизни что, согласно Ф. Зимбардо, 
проявлялось в эмоциональном равновесии отношения личности к собственному прошлому, настоящему и будущему [7]. Исследования временной перспективы как мотивационной установки ограничивались исследованиями протяженности (глубины) перспективы будущего и направленностью мотивационных объектов.

В настоящей статье представлены результаты исследований проблемы сбалансированности временной перспективы в отношении взрослых, занимающихся предпринимательством на протяжении более 15 лет и достигших различных результатов в своей деятельности. Исследования позволяют обосновать предположение о том, что эффективность деятельности в меньшей степени зависит от протяженности временной перспективы и в большей степени - от сбалансированности количества и направления мотивационных объектов, расположенных в перспективе будущего. Актуальность данного исследования связана с потребностью современного общества в понимании механизмов, влияющих на эффективность деятельности человека, определение ресурсов, необходимых для успешной самореализации личности. Как отмечает О.В. Лукьянов, само понятие успешности «указывает нам на проблему отношения психологических событий во времени, успешность - это значит своевременность», время задает направление и смыслы деятельности [8. С. 60].

Теоретическим обоснованием исследований стал ряд научных концепций, на которые наиболее часто опираются современные исследователи временной перспективы: пространственно-психологическая модель К. Левина; концепция временной перспективы как мотивационной установки Ж. Нюттена; причинно-следственная концепция Е.И. Головахи и А.А. Кроник; концепция личностной организации времени К.А. Абульхановой-Славской.

Впервые понятие временной перспективы ввел в науку К. Левин. В его пространственно-психологической модели сознание и поведение человека рассматривались через призму единства временной и пространственной перспективы. В представлениях К. Левина события прошлого в виде воспоминаний и события будущего в виде перспектив присутствуют в настоящем и определяют его. Согласно пространственно-психологической модели К. Левина, существуют единицы психологического времени, определяющего границы «психологического поля в данный момент» [10, 11]. Продолжая развивать взгляды К. Левина, П. Фресс, обосновал, что благодаря памяти мы можем реконструировать последовательность ранее пережитых изменений и предвосхищать подобные изменения в будущем [1].

В концепции Ж. Нюттена временной перспективой стали называть зону отдаленного будущего. Ж. Нюттен пошел по пути изучения временной перспективы как мотивационного образования, он разграничил временную перспективу, временную ориентацию и временную установку. В своих работах он писал: «Первый аспект - это временная перспектива в собственном значении этого слова, характеризующаяся, прежде всего, протяженностью, глубиной, насыщенностью, степенью структурированности и уровнем реалистичности. Второй аспект - временная установка, т.е. более или менее 
позитивная или негативная настроенность субъекта по отношению к прошлому, настоящему или будущему. Третий аспект - временная ориентация характеризуется поведением субъекта... мыслится как преимущественная, доминирующая направленность этого поведения на объекты и события прошлого, настоящего или будущего» [9. С. 354].

Далее Ж. Нюттен изучил временную перспективу как мотивационную характеристику и разработал метод мотивационных индукций (ММИ), локализующий мотивационные цели в темпоральных зонах. Этот подход в дальнейшем стали определять как мотивационный, его продолжили развивать В. Ленс, З. Залески, Т. Гисме. В. Ленс определил временную перспективу в категорию личностностных черт как мотивационную установку, влияющую на достижение цели. Согласно его когнитивно-мотивационной теории настойчивость в достижении цели понижается с увеличение временного расстояния [1]. Т. Гисме акцентировался на влиянии временной перспективы как мотивационных ориентаций на успех или неудачу. По его мнению, большее расстояние до цели оказывает меньшее влияние на цель. 3. Залески расширил представления В. Ленса и Т. Гисме и предположил, что долговременные цели могут достигаться только при условии существования промежуточных. Поэтому важным условием успешности достижения целей он видел способность человека планировать свою деятельность.

По-другому к изучению временной перспективы подошли представители событийного подхода, в частности Е.И. Головаха и А.А. Кроник. В их причинно-целевой концепции единицей анализа стала межсобытийная связь, которая может быть реализованной, актуальной и потенциальной. Они изучили влияние конгруэнтности психологического и хронологического возраста на реализованность личности и ее кризисы, такие как потеря смысла жизни. Основным понятием причинно-следственной концепции стало понятие «субъективная картина жизненного пути» как психический образ, отражающий события жизни и их взаимосвязи. Эти же идеи разделяли В.С. Хомик, Д.А. Леонтьев, Е.В. Камнева, Е.Ю. Мандрикова.

В свою очередь, К.А. Абульханова-Славская подошла к пониманию временной перспективы с позиции идеи изучения «жизненного пути», определенной С.Л. Рубинштейном в своих работах. Создав концепцию личностной организации времени, она утверждала, что психологическое время имеет определенную структуру: сознание, переживание, практическая организация. К.А. Абульханова-Славская ввела понятия «жизненная позиция», «жизненная линия» и «жизненная перспектива», при этом жизненная перспектива у нее сопоставляется с временной перспективой и разводится на отдельные виды: психологическую, личностную и собственно жизненную. Также ею были эмпирически выведены дополнительные компоненты временной перспективы: планирование и восприятие времени [12]. Продолжая это направление, В.И. Ковалев ввел понятие «трансперспектива» как способность в сознании интегрировать время своей жизни, «соединяя в настоящем прошлое и будущее». В рамках этого же подхода работали В.Ф. Серенкова, Л.Ю. Кублицкене, Н.Ю. Григоровская, Т.И. Березина. 
О.В. Лукьянов исследует понимание времени жизни с позиции экзистенциональных смыслов. В своих работах он развивает идею временной целостности через понятия трастемпоральности. Задачи личности он видит в понимании направленности своей собственной жизни и способности быть готовым «приводить в порядок свое настоящее», быть активным участником действительности, сохраняя неразрывность прошлого и будущего $[13,14]$.

В изучении психологического времени и временной перспективы в образовательной практике определенные результаты получили М.Р. Гинзбург, М.М. Бахтин, И.В. Дубровина, Н.Н. Толстых, О.В. Лукьянов и др. Первой характеристикой временной перспективы М.Р. Гинзбург считал организованность: на положительном полюсе она выступает как организованная (цели обеспечены средствами), на отрицательном - как неорганизованная (цели не обеспечены средствами). Вторая основная характеристика временной перспективы - протяженность, и чем она больше, тем человек более успешен: «...вторым основным показателем, характеризующим временное будущее, является его протяженность (на позитивном полюсе - долговременное, на негативном - кратковременное)», которая определяет особенности развития личности [15. С. 46]. А.А. Кроник и Е.И. Головаха придерживались таких же взглядов [16].

Вклад в методическое изучение временной перспективы внесли и зарубежные исследователи, такие как Э. Шостом, Т. Коттл, Ф. Мелджес, Н. Фезер, М. Бонд, Ф. Зимбардо, Р. Эммонс. Э. Шостом ввел шкалу «временная компетентность» в опросник для оценки самоактуализации. Т. Коттл разработал ряд простых в использовании методик: «Метод временной линии», «Циклический тест времени», методики «График жизни» и «Инвентарь длительности». Под перспективой будущего исследователь понимал «способность личности действовать в настоящем в свете представления отдаленных будущих событий» [17]. Ф. Зимбардо разработал методику для выявления основных темпоральных ориентаций личности. По его мнению, человек акцентируется на одном из времен в прошлом, настоящем или будущем и, как следствие, имеет доминирующий эмоциональный настрой [7. С. 28].

И.В. Дубровина и Н.Н. Толстых предложили психотехнику визуализации, представления и ведения дневниковых записей для работы с ближними и дальними целями.

На сегодняшний день остаются неразрешенными противоречия в определении основных аспектов временной перспективы и их связи с личностными характеристиками. Открыт вопрос о понимании системности качественных параметров временной перспективы и сочетании этих параметров у отдельных личностей. Частично эту задачу пытались решить в своих исследованиях Ж. Нюттен, М.Р. Гинзбург, А.А. Кроник, Е.И. Головаха. Внимание исследователей было сосредоточено на протяженности временной перспективы и целевой направленности мотивационных объектов. Они исходили из предположения, что протяженная временная перспектива, насыщенная мотивационными объектами, способствует самореализации 
личности. По Ж. Нюттену, «протяженная временная перспектива способствует постановке субъектом отдаленных целей и выработке долгосрочных поведенческих проектов»; субъект, который имеет короткую временную перспективу, будет неспособен найти средства и цели для удовлетворения своих потребностей [9. С. 385]. В противоположность этому утверждению К. Роджерс, А. Маслоу, Ф. Перлз предполагают, что «люди, в чьем поведении прошлое и будущее играют какую-то роль (т.е. люди с временной перспективой), не способны актуализировать собственные потенции (самоактуализироваться)», жизнь человека, погруженного только в настоящий момент, более эффективна, чем у того, кто строит воздушные замки [9. С. 377]. Обе точки зрения являются некими крайними точками континуума в понимании соотнесения связи временной перспективы личности с активностью и самореализованностью личности.

В проведенном исследовании была поставлена задача расширить представления о качественных характеристиках временной перспективы в их взаимозависимости с активностью в настоящем. Временная перспектива рассматривается как совокупность репрезентаций мотивационных объектов, расположенных на временной оси и детерминирующих направленность поведения личности в настоящем, при этом сама ось претерпевает определенные трансформации в субъективном представлении личности. Как отмечает Ж. Нюттен, «“объектный” (содержательный) аспект перспективы будущего состоит из целевых объектов и структур “средство-цель”, виртуально присутствующих в сознании индивида, действующего в актуальной ситуации. Цели встроены в перспективу будущего и перспективу будущего нельзя разделять с ними» [9. С. 381]. Сама перспектива будущего строится на основе репрезентации мотивационных объектов, расположенных в определенных темпоральных зонах. Мотивационная природа временной перспективы выступает как целевой активатор поведения в настоящем, содержание и расположение объектов в темпоральных зонах взаимосвязано с направленностью активности деятельности и величиной ее проявления.

В исследовании были полученные результаты, характерные для российской культуры с ее историческими аспектами. Считаем данное уточнение необходимым, так как временная перспектива личности не может рассматриваться без учета социокультурного пространства, культурно-историческая среда которого накладывает свой отпечаток на представления личности о себе. В исследовании был сделан акцент на изучение отличительных особенностей временной перспективы в структурном, содержательном и описательном аспектах и выдвинуто предположение о том, что временная перспектива имеет различные виды в зависимости от по насыщенности мотивационными объектами, направленности мотивационных объектов, развернутости репрезентации.

Для исследования параметров временной перспективы была использована методика мотивационных индукций Ж. Нюттена МІМ в адаптации Д.А. Леонтьева. Для определения способности личности к эффективному осуществлению деятельности в настоящем был применен метод личностного 
интервью, в котором респонденты рассказывают о своем жизненном пути предпринимателя, отмечая временные периоды значительных изменений в процессе своей жизни. Кроме этого, использовалась внешняя оценка деятельности участников эксперимента по успешности функционирования предприятия.

Обработка и анализ данных проводились с помощью статистической программы SPSS17.0 с использованием $U$-критерия Манна-Уитни.

В исследовании было выдвинуто предположение, что по общей насыщенности мотивационными объектами временная перспектива может иметь различные виды: «обедненный», при котором временная перспектива имеет ограниченное количество мотивационных объектов; «умеренно насыщенный», во временной перспективе представлено оптимальное количество мотивационных объектов, затрагивающих разные стороны жизни человека; «квазинасыщенный», предполагающий расположение большого количества мотивационных объектов, превышающее оптимальный уровень.

Также было сделано предположение, что существуют отличия временной перспективы по параметру направленности: «направленная на проблему» и «направленная на жизнь». Направленная на проблему временная перспектива содержит мотивационные объекты, так или иначе связанные с одной или двумя актуальными проблемными темами, и минимальное количество объектов, направленных на другие жизненные потребности. Направленная на жизнь временная перспектива содержит разнообразие мотивационных объектов, отражающих потребности в различных жизненных сферах человека.

Еще одной отличительной качественной характеристикой временной перспективы может выступать развернутость репрезентации объектов, то, как человек формулирует свою потребность в доступную для понимания форму. Репрезентации могут быть «ясно представленные», т.е. сформулирован мотивационный объект, имеющий понятное смысловое содержание, в форме фразы или целого предложения, и «неясно представленные», с неясным смысловым значением, чаще всего в форме одного метафорического слова.

Был выдвинут ряд предположений относительно взаимосвязи отдельных характеристик временной перспективы с эффективностью деятельности личности в настоящем:

- общее малое количество объектов свидетельствует о периоде стагнации в развитии и самореализации личности. При этом временная перспектива имеет направленность на проблему. У личности, находящейся в кризисном или посткризисном состоянии, субъективное восприятие жизни и себя сужено, и временная перспектива в этом случае ограничивается малым набором мотивационных объектов, имеет короткую протяженность и сосредоточена вокруг одной или двух субъективно определяемых проблем. В данной ситуации не наступает самореализация, личность находится в процессе самосохранения, самовыживания. Важно учитывать, что мы имеем дело с психически сложной личностью, с высокой самоорганизованностью, здесь не идет речь о индивидах с упрощенной психической организацией, 
с временной перспективой, изначально обедненной, наполненной примитивными, чаще биологическими потребностями и имеющей короткую протяженность;

- квазинасыщеная временная перспектива имеет направленность на проблему. Личность в настоящем проявляет высокую активность в области проблемы, однако это не дает желаемых результатов. Самореализация в этом случае не наступает, человек предпринимает бесчисленные попытки продвинуться в достижении своей цели, но каждый раз оказывается на том же уровне;

- оптимально насыщенная временная перспектива с направленностью на жизнь будет у самореализующейся личности, активность деятельности которой имеет продуктивный характер и приводит к достижению желаемых результатов;

- ясность и неясность репрезентации напрямую связана с личностными смыслами субъективного восприятия и с тем, насколько осознанно переживаются события жизни.

С целью проверки достоверности выдвинутых гипотез было проведено исследование с участием людей, занимающихся на настоящий момент или занимавшихся предпринимательством. Сама предпринимательская деятельность, по определению И.И. Беккер, сложна в осуществлении и требует сочетания определенных особенностей личности, относящихся к эмоционально-волевой, мотивационной, когнитивной, коммуникативной сферам [18], что соотносится с возможностью самореализации личности. Эффективность деятельности участников оценивалась по экономическим показателям принадлежащих им и управляемых ими производственных предприятий.

Всего в исследовании приняли участие 42 человека в возрасте от 40 до 70 лет, в том числе 11 женщин и 31 мужчина. Все участники исследования являются предпринимателями, начавшими свою предпринимательскую деятельность более 15 лет назад (1990-2000 гг.). На первом этапе участники были поделены на три группы по критериям стабильности и эффективности предпринимательской деятельности. Первую группу составили предприниматели, успешно осуществляющие собственную предпринимательскую деятельность на протяжении более 15 лет. Вторую группу составили те, кто начинали и некоторое время достаточно эффективно осуществляли свою предпринимательскую деятельность, но затем отказались ее продолжать и перешли на работу в чужие предприятия в качестве наемных сотрудников. В третью группу вошли лица, которые на протяжении более 15 лет активно пытаются организовать и развить собственное дело, но в настоящее время так и находятся на начальном этапе. Распределение проводилось на основании интервью и внешней оценки: в 1-ю группу успешных, стабильно и эффективно действующих вошли 15 человек; во 2-ю группу сменивших направление, работающих наемными сотрудниками или в настоящий момент не работающих - 15 человек; в 3-ю группу нестабильных - 10 человек; 2 человека не вошли ни в одну из групп. 
Сравнительный анализ полученных результатов по параметру общего объема мотивационных объектов, репрезентируемых в перспективе будущего, выявил различие временной перспективы личностей с различной эффективностью деятельности: наибольшее количество мотивационных объектов было выявлено у 3-й группы (нестабильные), наименьшее количество у 2-й группы (сменившие направление деятельности), среднее значение у 1-й группы (успешно действующие). Различия между 3-й и 2-й группами имеют величину ранговых различий $U=0,001$ ( $p<0,01)$, между 3-й и 1-й группами $U=0,038(p<0,05)$, между 1-й и 2-й группами $U=0,013(p<0,05)$.

Анализ насыщенности отдельных темпоральных зон показал характерные особенности распределения общего объема мотивационных объектов по всей оси временной перспективы для разных групп участников исследования. Меньшее количество мотивационных объектов у 1-й группы по сравнению с 2-й и 3-й группами находится в темпоральной зоне «настоящий момент»; личности, успешные в собственной деятельности, в меньшей степени акцентируют внимание на целях, расположенных во времени на расстоянии от нескольких месяцев и в отдаленном будущем. Большое количество мотивационных объектов в темпоральной зоне «год» коррелирует с повышенной активностью личности, что характерно для 3-й группы. У 2-й группы выявилось меньшее количество объектов, по сравнению с 1-й и 3-й группами, в темпоральной зоне «открытое настоящее». Результаты, полученные в исследовании, достоверные различия между группами по критерию насыщенности мотивационными объектами темпоральных зон приведены в табл. 1.

Таблица 1

Сравнение групп по насыщенности объектами темпоральных зон

\begin{tabular}{|l|c|c|c|c|}
\hline \multirow{2}{*}{ Темпоральная зона } & \multicolumn{2}{|c|}{ Mean Rank } & \multirow{2}{*}{$\begin{array}{c}\text {-кри- } \\
\text { терий }\end{array}$} & $p$ \\
\cline { 2 - 5 } & $\begin{array}{c}\text { Успешные } \\
\text { (1-я группа) }\end{array}$ & $\begin{array}{c}\text { Нестабильные } \\
\text { (3-я группа) }\end{array}$ & \multicolumn{1}{|c|}{$p$} \\
\hline Текущий момент & 9,27 & 13,81 & 0,028 & $<0,05$ \\
\hline Месяц & 9,00 & 13,00 & 0,054 & $<0,10$ \\
\hline Год & 8,92 & 14,38 & 0,049 & $<0,05$ \\
\hline
\end{tabular}

\begin{tabular}{|l|c|c|c|c|}
\hline \multirow{2}{*}{ Темпоральная зона } & \multicolumn{2}{|c|}{ Mean Rank } & \multirow{2}{*}{$\begin{array}{c}\text {-кри- } \\
\text { терий }\end{array}$} & $p$ \\
\cline { 2 - 3 } & $\begin{array}{c}\text { Сменившие направ- } \\
\text { ление (2-я группа) }\end{array}$ & $\begin{array}{c}\text { Нестабильные } \\
\text { (3-я группа) }\end{array}$ & 0,002 & $<0,01$ \\
\hline Год & 8,83 & 17,94 & 0,006 & $<0,01$ \\
\hline Настоящее продолженное & 9,20 & 17,25 & 0,006 & $<0,10$ \\
\hline Прошлое & 10,17 & 15,44 & 0,059 & \\
\hline
\end{tabular}

\begin{tabular}{|c|c|c|c|c|}
\hline \multirow[b]{2}{*}{ Темпоральная зона } & \multicolumn{2}{|c|}{ Mean Rank } & \multirow[b]{2}{*}{$\begin{array}{l}U \text {-кри- } \\
\text { терий }\end{array}$} & \multirow[b]{2}{*}{$p$} \\
\hline & $\begin{array}{c}\text { Успешные } \\
\text { (1-я группа) }\end{array}$ & \begin{tabular}{|l} 
Сменившие направ- \\
ление (2-я группа)
\end{tabular} & & \\
\hline Текущий момент & 11,96 & 16,70 & 0,045 & $<0,05$ \\
\hline Настоящее продолженное & 18,42 & 11,10 & 0,018 & $<0,05$ \\
\hline Жизнь & 19,12 & 10,50 & 0,005 & $<0,01$ \\
\hline Субъективная старость & 17,12 & 12,23 & 0,048 & $<0,05$ \\
\hline
\end{tabular}


Сравнительный анализ направленности мотивационных объектов в группах показал, что существуют различия в приоритетах мотивационных презентаций для личностей с различной эффективностью деятельности. Направленность на деятельность предпочтительнее для личностей, на текущий период жизни не сумевших добиться значимых результатов в сфере предпринимательства (3-я группа). Наоборот, участники 2-й группы (сменившие направление), отказавшиеся от попыток самореализации в сфере самостоятельного предпринимательства, имеют наименьшее количество объектов, направленных на деятельность, в том числе на рабочую. Очевидно, для успешности в деятельности личность должна иметь определенное количество мотивационных объектов, направленных на деятельность, но при этом сохранять баланс распределения своего внимания и на другие сферы жизнедеятельности. Результаты сравнения групп по направленности на познание выявили отличия 3-й группы, которая имеет большее количество объектов, чем в двух других группах. Возможно, это связано с общей высокой активностью или с неуверенностью личности в собственной компетентности. По общей направленности на личность субъекта (мотивация, относящаяся к целостности личности и к отдельным ее характеристикам) выделяется 1-я группа (успешные), при этом наибольшее количество мотивационных объектов связано с сохранением здоровья и экономического благополучия. Частные различия выявлены по направлению «взаимодействие с другими» (социальные контакты): 2-я группа имеет меньшее количество объектов по сравнению с 3-й; 3-я группа - большее количество по сравнению с 1-й. Выявленные значимые различия между группами по направленности мотивационных объектов представлены в табл. 2.

Таблица 2

Сравнение групп по направленности мотивационных объектов во временной перспективе

\begin{tabular}{|c|c|c|c|c|}
\hline \multirow[b]{2}{*}{ Темпоральная зона } & \multicolumn{2}{|c|}{ Mean Rank } & \multirow{2}{*}{$\begin{array}{l}U \text {-кри- } \\
\text { терий }\end{array}$} & \multirow[b]{2}{*}{$p$} \\
\hline & $\begin{array}{c}\text { Успешные } \\
\text { (1-я группа) }\end{array}$ & $\begin{array}{c}\text { Нестабильные } \\
\text { (3-я группа) }\end{array}$ & & \\
\hline Деятельность (активность) & 8,92 & 14,38 & 0,036 & $<0,05$ \\
\hline Познание & 9,35 & 13,69 & 0,094 & $<0,10$ \\
\hline Личность субъекта & 12,65 & 8,31 & 0,045 & $<0,05$ \\
\hline $\begin{array}{l}\text { Сохранность здоровья и эко- } \\
\text { номического благополучия }\end{array}$ & 13,42 & 7,06 & 0,019 & $<0,05$ \\
\hline
\end{tabular}

\begin{tabular}{|c|c|c|c|c|}
\hline \multirow[b]{2}{*}{ Темпоральная зона } & \multicolumn{2}{|c|}{ Mean Rank } & \multirow{2}{*}{$\begin{array}{l}U \text {-кри- } \\
\text { терий }\end{array}$} & \multirow[b]{2}{*}{$p$} \\
\hline & $\begin{array}{c}\text { Сменившие направ- } \\
\text { ление (2-я группа) }\end{array}$ & $\begin{array}{c}\text { Нестабильные } \\
\text { (3-я группа) }\end{array}$ & & \\
\hline Деятельность (активность) & 9,07 & 17,50 & 0,004 & $<0,01$ \\
\hline Рабочая деятельность & 9,67 & 16,38 & 0,006 & $<0,01$ \\
\hline Познание & 9,50 & 16,69 & 0,005 & $<0,01$ \\
\hline Ожидание действий от других & 10,13 & 15,50 & 0,061 & $<0,05$ \\
\hline $\begin{array}{l}\text { Ожидание изменений в } \\
\text { стране }\end{array}$ & 10,30 & 15,19 & 0,095 & $<0,10$ \\
\hline
\end{tabular}


Окончание табл. 2

\begin{tabular}{|c|c|c|c|c|}
\hline \multirow[b]{2}{*}{ Темпоральная зона } & \multicolumn{2}{|c|}{ Mean Rank } & \multirow[b]{2}{*}{$\begin{array}{l}U \text {-кри- } \\
\text { терий }\end{array}$} & \multirow[b]{2}{*}{$p$} \\
\hline & $\begin{array}{c}\text { Успешные } \\
\text { (1-я группа) }\end{array}$ & $\begin{array}{l}\text { Сменившие направ- } \\
\text { ление (2-я группа) }\end{array}$ & & \\
\hline Взаимодействие с другими & 18,65 & 10,90 & 0,029 & $<0,05$ \\
\hline Переживания о других & 18,08 & 11,40 & 0,012 & $<0,05$ \\
\hline Личность субъекта & 19,77 & 9,93 & 0,080 & $<0,10$ \\
\hline $\begin{array}{l}\text { Сохранность здоровья и эко- } \\
\text { номического благополучия }\end{array}$ & 17,38 & 12,00 & 0,005 & $<0,01$ \\
\hline Религия & 13,00 & 15,80 & 0,094 & $<0,10$ \\
\hline
\end{tabular}

На втором этапе анализа полученных результатов была предпринята попытка сравнить распределение общего количества мотивационных объектов по темпоральным зонам на оси временной перспективы для различных групп. Полученные результаты представлены на рис. 1. Распределение объектов по оси временной перспективы оказалась достаточно равным относительно общего количества мотивационных объектов для всех групп. Отличия выявились для 3-й группы, где пик размещения объектов приходится на темпоральную зону «год», что предполагает смещение основной направленности активности участников этой группы на цели, достигаемые в течении одного года, причем это могут быть как активные действия, так и пассивные ожидания каких-то изменений в своей жизни. Рис. 1 показывает, что личности, успешно осуществляющие свою деятельность, имеют сбалансированную временную перспективу относительно оси времени, количество мотивационных объектов равномерно представлено для равных темпоральных зон и имеется среднее значение общего количества объектов. Личности с несбалансированной и квазизагруженной временной перспективой имеют высокий профиль и концентрацию целевых объектов в темпоральной зоне «год». Сбалансированная относительно оси времени временная перспектива, но обедненная по количеству самих объектов, выявляется у личностей, переживающих стагнацию в своей деятельности.

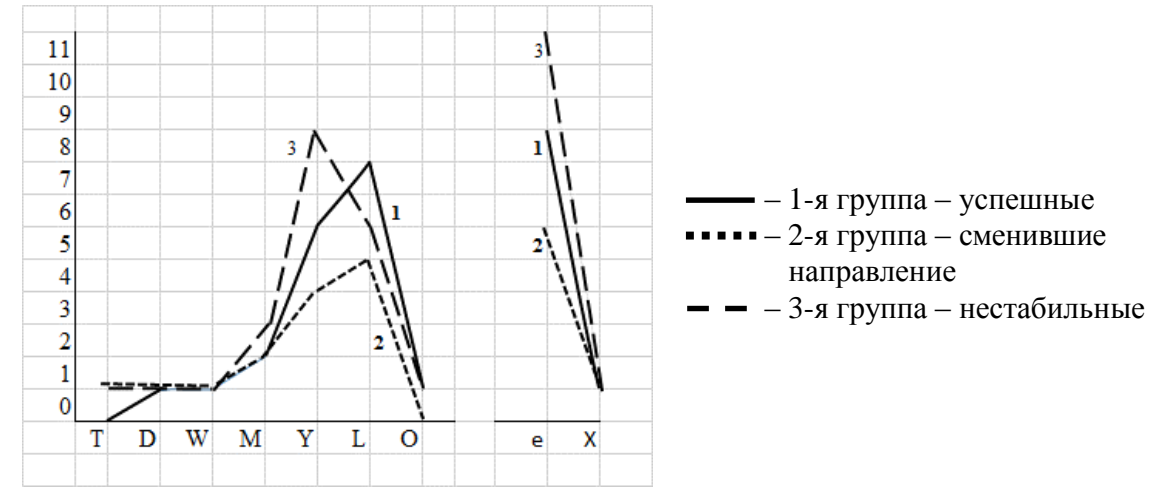

Рис. 1. Профили временной перспективы по загруженности мотивационными объектами отдельных темпоральных зон. По оси $Y$-среднее количество объектов для группы; по оси $X$ - темпоральные зоны: $D$ - день; $W$ - неделя; $M$ - месяц; $Y$ - год; $L$ - вся жизнь; $O$ - старость; $e$ - открытое настоящее; $X$ - историческое время или время после смерти 
Полученные результаты подтверждают предположение о том, что эффективность и результативность деятельности невозможны при несбалансированной временной перспективе. С одной стороны, ограниченная в протяженности и объеме мотивационных объектов временная перспектива, соответственно низкая активность личности негативно сказываются на самореализации этой личности. С другой стороны, повышенная активность, связанная с перенасыщенной временной перспективой, не дает личности определить и сосредоточить свою активность на достижении наиболее значимой цели. Происходит «распыление» усилий на различные цели или, как вариант, основная цель личности имеет большую вариативность, чем осложняется планомерное достижение этой цели. И только при сбалансированной временной перспективе личность способна целенаправленно направлять свои усилия на достижение намеченных целей, при этом проявляя достаточную активность.

Отдаленные цели, долгосрочное планирование делают возможным прогрессивное движение личности в своей самореализации, но именно при активном внимании к потребностям настоящего можно ожидать осознанности проживания жизни, эффективности деятельности и удовлетворенности от этой деятельности. Баланс сосредоточенности на дальних и ближних целях (мотивационных объектах) является основой целенаправленной эффективной деятельности, в то же время нарушение баланса негативно влияет на самовосприятие и самореализацию личности. Сбалансированность разнообразия целевой активности будет определять способность личности концентрироваться на главных целевых направлениях деятельности, при этом осознанно участвовать в проживании своей жизни в настоящий период. С одной стороны, обедненное мотивационное содержание временной перспективы ограничивает личность в видении богатства возможностей, которые предоставляет жизнь, и, следовательно, в деятельной активности, а с другой стороны, слишком большое целевое разнообразие временной перспективы приводит к потере понимания смысла и осознания достигнутых целей, личность не успевает ассимилировать полученный опыт, в результате не наступает осознанного удовлетворения от собственной деятельности.

В заключение можно утверждать, что активно и эффективно действующие личности имеют сбалансированную временную перспективу по количеству мотивационных объектов и их распределению на оси времени, при этом объекты имеют разнообразную целевую направленность. Личности, действующие активно, но неэффективно, имеют перенасыщенную временную перспективу по количеству мотивационных объектов и сосредоточение большинства мотивационных объектов на темпоральной зоне «год», при этом существует целевая направленность на проблему, в данном случае на рабочую деятельность как проблемную зону. Личности, по каким-либо причинам не сумевшие продолжать активную и эффективную деятельность в выбранном направлении и поэтому сменившие направление своей деятельности, имеют обедненную временную перспективу по количеству мотивационных объектов при сбалансированном распределение на оси времени. 
Полученные результаты позволяют сформировать программу дальнейших направлений изучения сбалансированности временной перспективы и ее взаимозависимости с личностными характеристиками человека. Пока за рамками исследования остался вопрос о возрастных различиях границ сбалансированности временной перспективы. Также предполагается разработка методик, позволяющих изменять сбалансированность временной перспективы личности, оказывая влияние на успешность ее самореализации.

\section{Лuтература}

1. Мандрикова Е.Ю. Современные подходы к изучению временной перспективы личности // Психологический журнал. 2008. Т. 29, № 4. С. 54-65.

2. Афанасьева А.Н. Личность как субъект жизненного пути // Молодой ученый. 2013. № 10. C. 475-478.

3. Ермолова И.М., Штрахова А.В. Временная перспектива и переживания безнадежности в структуре внутренних форм суицидального поведения // Вестник Южно-Уральского государственного университета Сер. Психология. 2015. Т. 8, № 4. С. 39-51.

4. Караваева Л.П., Особенности представления о будущем в период середины жизни личности у людей с разной временной перспективой // Человеческий капитал. 2013. № 4 (52). С. 23-27.

5. Лукьянов О.В., Неяскина Ю.Ю. Смысловые детерминанты временной перспективы личности // Вестник Томского государственного университета. 2012. № 360. С. 152-157.

6. Ширяева О.С., Навроцкая Е.А. Временная перспектива личности при разных типах оценки среды жизнедеятельности // Вестник КРАУНЦ. Гуманитарные науки. 2011. № 2. С. $108-118$.

7. Зимбардо Ф., Бойд Дж. Парадокс времени. Новая психология времени, которая улучшит вашу жизнь. СПб. : Речь, 2010. 352 с.

8. Лукьянов О.В. Принцип транстемпоральности в решении вопроса успешности актуальности психологической практики // Сибирский психологический журнал. 2007. № 25. С. 59-66.

9. Нюттен Ж. Мотивация, действие и перспектива будущего / под ред. Д.А. Леонтьева. М. : Смысл, 2004. 608 с.

10. Зейгарник Б.В. Теория личности Курта Левина. М. : Изд-во Моск. ун-та, 1981. 181 с.

11. Левин К. Динамическая психология : избранные труды. М. : Смысл, 2001. 572 с.

12. Абульханова К.А., Березина Т.Н. Время личности и время жизни. СПб. : Алетейя, $2001.304 \mathrm{c}$.

13. Лукьянов О.В. Готовность быть: введение в транстемпоральную психологию. М. : Смысл, 2009. $231 \mathrm{c.}$

14. Лукьянов О.В. Экзистенциальный анализ и природа времени. Транстемпоральный характер экзистенциального опыта // Вестник Томского государственного университета. 2007. № 299. С. 164-170.

15. Гинзбург М.Г. Психологическое содержание личностного самоопределения // Вопросы психологии. 1994. № 3. С. 43-53.

16. Головаха Е.И. Психологическое время личности. Киев : Наукова думка, 1984. 207 с.

17. Белинская Е.П., Давыдова И.С. Графический тест Коттла: специфика показателей временной перспективы // Психологическая наука и образование. 2007. № 5.С. 28-37.

18. Беккер И.И. Временная перспектива как характеристика личности предпринимателя // Социология и право. 2013. № 2 (19). С. 41-46. 


\section{Сведение об авторе:}

ПОПОВА Оксана Николаевна, психолог Городского центра психолого-педагогической поддержки молодежи «Родник» (Новосибирск, Россия), аспирант Новосибирского государственного педагогического университета. E-mail: ankor-akc@yandex.ru

\section{THE PROBLEM OF A PERSON'S TIME PERSPECTIVE BALANCE}

Siberian journal of psychology, 2017, 66, 18-31. DOI: 10.17223/17267080/66/2

Popova Oksana N. Novosibirsk Center for psychological and pedagogical support of youth "Rodnik", Novosibirsk State Pedagogical University (Novosibirsk, Russian Federation). E-mail: ankor-akc@yandex.ru

Keywords: time perspective; motivational objects; temporal zones; time perspective balance; focus of motivational objects; length of time perspective.

During the last decade in foreign and domestic scientific works the attention to the phenomenon of psychological time and temporal perspective as a characteristic of the personality increased [13]. In modern science, we research the problem of temporal perspective in a wide range of approaches, such as affective aspects of the temporal perspective associated with the emotional attitude to the events of the past and the present (F. Simbardo, J. Boyd, M. R. Khachaturov, A. K. Bolotova, etc.); features of perception of the subjective time of life and its organization (K.A. Abulkhanova-Slavskaya, T.N. Berezina, L.P. Karavaeva, A.N. Afanasieva, etc.); Prospects for the future as a motivational attitude that influences the achievement of the goal (J. Nutten, V. Lens, T. Gisme, Z. Zaleski); the structure of inter-event links (E.I. Golovakha and A.A. Kronik, etc).

This article presents the results of research of the time perspective balance problem among adults who have been engaged in business for more than 15 years and have achieved various results in their activities. The research allows us justifying the assumption that the effectiveness of the activity depends more on the balance of the amount and direction of motivational objects, which are located in the future perspective, than on the length of the time perspective. The relevance of this study is connected with the need of modern society at understanding the mechanisms influencing the effectiveness of human activity, and at understanding the resources which are necessary for successful self-realization of the individual. In total, 42 people from 40 to 70 participated in this study, including 11 women and 31 men. All participants are entrepreneurs who started their entrepreneurial activity more than 15 years ago (1990-2000).

We may confirm that individuals, who operate actively and effectively, have a balanced time perspective for the amount of motivational objects and their distribution on the axis of time, while the objects have a diverse target orientation. Individuals, who operate actively but ineffectively, have an oversaturated time horizon at the number of motivational objects and the concentration of most motivational objects at the temporal zone "year", while there is a targeted focus to the problem, in this case "working activity", as a problem zone. Individuals, who failed to continue active and effective work in the chosen direction and therefore changed their direction of activity, have a depleted time perspective for the number of motivational objects, with a balanced distribution on the time axis.

\section{References}

1. Mandrikova, E.Yu. (2008) Sovremennye podkhody k izucheniyu vremennoy perspektivy lichnosti [Modern approaches to the study of the temporal perspective of personality]. Psikhologicheskiy zhurnal. 29(4). pp. 54-65.

2. Afanasieva, A.N. (2013) Lichnost' kak sub"ekt zhiznennogo puti [Personality as the subject of life's path]. Molodoy uchenyy. 10. pp. 475-478.

3. Ermolova, I.M. \& Shtrakhova, A.V. (2015) Vremennaya perspektiva i perezhivaniya beznadezhnosti v strukture vnutrennikh form suitsidal'nogo povedeniya [Temporal perspective 
and experiences of hopelessness in the structure of internal forms of suicidal behaviour]. Vestnik Yuzhno-Ural'skogo gosudarstvennogo universiteta Ser. Psikhologiya. 8(4). pp. 39-51.

4. Karavaeva, L.P. (2013) Osobennosti predstavleniya o budushchem v period serediny zhizni lichnosti u lyudey s raznoy vremennoy perspektivoy [The idea of future in the middle-aged people with different time horizons]. Chelovecheskiy kapital. 4(52). pp. 23-27.

5. Lukyanov, O.V. \& Neyaskina, Yu.Yu. (2012) Meaning determinants of personality's temporal perspective. Vestnik Tomskogo gosudarstvennogo universiteta. 360. pp. 152-157. (In Russian).

6. Shiryaeva, O.S. \& Navrotskaya, E.A. (2011) Vremennaya perspektiva lichnosti pri raznykh tipakh otsenki sredy zhiznedeyatel'nosti [The temporal perspective of the personality with different types of assessment of the life environment]. Vestnik KRAUNTs. Gumanitarnye nauki. 2. pp. $108-118$.

7. Zimbardo, F. \& Boyd, G. (2010) Paradoks vremeni. Novaya psikhologiya vremeni, kotoraya uluchshit vashu zhizn' [The Paradox of Time. A new time psychology that will improve your life]. Translated from English by O. Gatanova. St. Petersburg: Rech'.

8. Lukyanov, O.V. (2007) Principle of transtemporality in actual psychological practice. Sibirskiy psikhologicheskiy zhurnal - Siberian Journal of Psychology. 25. pp. 59-66. (In Russian).

9. Nutten, J. (2004) Motivatsiya, deystvie i perspektiva budushchego [Motivation, action and the prospect of the future]. Translated from French by E. Pyataeva, N. Tolstykh, V. Shevyakhova. Moscow: Smysl.

10. Zeygarnik, B.V. (1981) Teoriya lichnosti Kurta Levina [Kurt Levin's theory of personality]. Moscow: Moscow State University.

11. Levin, K. (2001) Dinamicheskaya psikhologiya [Dynamic Psychology]. Moscow: Smysl.

12. Abulkhanova, K.A. \& Berezina, T.N. (2001) Vremya lichnosti $i$ vremya zhizni [Personal time and time of life]. St. Petersburg: Aleteyya.

13. Lukyanov, O.V. (2009) Gotovnost' byt': vvedenie v transtemporal'nuyu psikhologiyu [Willingness to be: an introduction to transtemporal psychology]. Moscow: Smysl.

14. Lukyanov, O.V. (2007) Ekzistentsial'nyy analiz i priroda vremeni. Transtemporal'nyy kharakter ekzistentsial'nogo opyta [Existential analysis and the nature of time. The transtemporal character of existential experience]. Vestnik Tomskogo gosudarstvennogo universiteta - Tomsk State Univversity. 299. pp. 164-170.

15. Ginzburg, M.G. (1994) Psikhologicheskoe soderzhanie lichnostnogo samoopredeleniya [Psychological content of personal self-determination]. Voprosy psikhologii. 3. pp. 43-53.

16. Golovakha, E.I. (1984) Psikhologicheskoe vremya lichnosti [Psychological time of personality]. Kyev: Naukova dumka.

17. Belinskaya, E.P. \& Davydova, I.S. (2007) Graficheskiy test Kottla: spetsifika pokazateley vremennoy perspektivy [Cottle's graphical test: specificity of indicators of time perspective]. Psikhologicheskaya nauka i obrazovanie - Psychological Science and Education. 5. pp. 28-37.

18. Bekker, I.I. (2013) Vremennaya perspektiva kak kharakteristika lichnosti predprinimatelya [Temporary perspective as a characteristic of the entrepreneur's personality]. Sotsiologiya $i$ pravo. 2(19). pp. 41-46. 